Article

\title{
Multifunctional Silicone Rubber Nanocomposites by Controlling the Structure and Morphology of Graphene Material
}

\author{
Ruben Sanchez-Hidalgo ${ }^{1}{ }^{(\mathbb{D}}$, Clara Blanco ${ }^{1}$, Rosa Menendez ${ }^{1}$, Raquel Verdejo ${ }^{2}$ and \\ Miguel A. Lopez-Manchado $2, *$ (D) \\ 1 Instituto Nacional del Carbón, INCAR-CSIC, Apartado 73, 33080 Oviedo, Spain; \\ ruben@incar.csic.es (R.S.-H.); clara@incar.csic.es (C.B.); rosmenen@csic.es (R.M.) \\ 2 Instituto de Ciencia y Tecnología de Polímeros, ICTP-CSIC, 28006 Madrid, Spain; rverdejo@ictp.csic.es \\ * Correspondence: lmanchado@ictp.csic.es; Tel.: +34-912-587-630
}

Received: 21 January 2019; Accepted: 4 March 2019; Published: 8 March 2019

check for updates

\begin{abstract}
Multifunctional elastomer nanocomposites have been applied in several high-tech fields. The design of materials with tailored properties capable of tuning their performance is a topical challenge. Here, we demonstrate that it is possible to modulate the mechanical and transport properties of silicone rubber nanocomposites by controlling the structure, chemical composition and morphology of the graphene material. Intrinsic graphene properties, such as remaining oxygen groups, specific surface area, and aspect ratio, among others, have a profound effect on the final properties of the nanocomposite. Thus, the thermal conductivity benefits from larger filler size and high aromatic restoration. Whereas mechanical properties and electrical conductivity require a proper balance between filler/polymer matrix interaction and a partial aromatic restoration.
\end{abstract}

Keywords: silicone rubber; graphene; mechanical properties; transport properties; nanocomposites

\section{Introduction}

Silicone rubber (SR) is one of the most important synthetic elastomers since it possesses excellent properties, like high elasticity, high thermal stability, resistance to solvents and engine oils, biocompatibility, optical transparency, etc. [1]. Thus, silicone rubber finds use in high-tech applications, such as sealing, gas and aerospace industry, microfluidics, flexible electronics, medical devices, and electrical insulators, among others [2-6]. However, silicone rubbers usually require the use of fillers to improve their mechanical strength and stiffness. Recently, different graphene materials (GMs), thanks to their outstanding properties [7-9], have demonstrated to be a potential ideal reinforcement for silicone rubbers owing to its extraordinary mechanical properties and excellent electrical and thermal conductivity [10-17]. Developing high performance rubber nanocomposites using multifunctional fillers is one of the main current industrial challenges, since they combine the unique excellent elasticity of elastomers and different functionalities, as electrical or thermal conductive and permeability properties [18,19]. For instance, Song et al. [10] observed improvements of more than $50 \%$ in the thermal conductivity and an increase of about $140 \%$ in the tensile strength by addition of $8 \mathrm{wt} \%$ of graphene nanoplatelets. Other authors [12-14] have demonstrated that the surface treatment of GMs with silane improves the mechanical behavior, thermal stability and thermal conductivity of the composite material, due to a better dispersion and interaction of the graphene with the silicone rubber. Song et al. [15] developed silicone rubber/graphene multilayered films by a layer-by-layer assembly approach, with an exceptionally high thermal conductivity and stretchability. The films exhibited a highly ordered lamellar structure with a preferential orientation of the graphene, which 
provided continuous thermally conductive pathways. Additionally, the multilayered films with 40 assembly cycles had a thermal conductivity of $2.03 \mathrm{~W} / \mathrm{mK}$ in the horizontal direction. In a recent study, Wang et al. [17] analyzed the effect of the size of reduced graphene oxides (rGO) sheets on the properties of silicone composites. The authors observed that a middle-sized rGO sheet, of approximately $2.1 \mu \mathrm{m}$, had the best mechanical and thermal properties. However, there are no detailed studies concerning the effect of the structure, chemical composition or morphology of the graphene on the physical and mechanical properties of silicone rubber composites.

Our research group has developed a production method that enables the control of different characteristics of graphene materials (GMs), such as specific surface area, oxygen content and lateral size, through the knowledge of the used parent graphite and by tuning the exfoliation/reduction temperatures of the graphene oxide [20-22]. In the present study, seven graphene materials were selected to evaluate the role of their structure, morphology and chemical composition on the mechanical behavior and transport properties of silicone rubber composites.

\section{Materials and Methods}

\subsection{Materials}

Commercial synthetic graphite powder ( $<20 \mu \mathrm{m}$ Ref. 282863$)$, sulfuric acid $(98 \%)$, sodium nitrate $(>99.8 \%)$ and potassium permanganate $(<99 \%)$ were purchased from Sigma-Aldrich (Darmstadt, Germany). Methyl vinyl silicone rubber under the trade name Bluesil MF135U was kindly supplied by Bluestar Silicones France S.A.S., and bis(1-methyl-1-phenylethyl) peroxide (DCP) was used as vulcanizing agent.

\subsection{Synthesis of Thermally Reduced Graphene Oxide (TRGO)}

The graphite oxide was prepared from commercial graphite following a previously described modified Hummers' method [20,21]. Briefly, concentrated $\mathrm{H}_{2} \mathrm{SO}_{4}(360 \mathrm{~mL})$ was added to a mixture of graphite $(7.5 \mathrm{~g})$ and $\mathrm{NaNO}_{3}(7.5 \mathrm{~g})$ and followed by a careful addition of $\mathrm{KMnO}_{4}(45 \mathrm{~g})$. The solution was heated to $35{ }^{\circ} \mathrm{C}$ and stirred for $3 \mathrm{~h}$. Finally, $3 \% \mathrm{H}_{2} \mathrm{O}_{2}(1.5 \mathrm{~L})$ was slowly added to the reactor and stirred for $30 \mathrm{~min}$ and, subsequently, centrifuged (4000 rpm for $10 \mathrm{~min}$ ). The remaining solid material was washed with deionized water, centrifuged until neutral $\mathrm{pH}$ and vacuum dried. The thermally reduced graphene oxides (TRGOs) were obtained by thermal exfoliation/reduction from graphite oxide at five temperatures, $400,500,700,1000$ and $2000^{\circ} \mathrm{C}$ as described elsewhere [22,23]. The obtained samples were labeled as TRGO-T, where $\mathrm{T}$ is the temperature used in the reduction process.

\subsection{Preparation of TRGO Filled Silicone Rubber Composites}

The composites were prepared in an open two-roll mill (Comerio Ercole S.P.A.) at room temperature. The rotors operated at a speed ratio of 1:1.4. TRGOs at different concentrations $(1,3$ and $5 \mathrm{phr}$ (parts per hundred of rubber)) were added to the rubber before incorporating the peroxide. The concentration of DCP in the composite is $0.6 \mathrm{phr}$. The optimum vulcanization time (Table 3 ), $t_{90}$, was determined by a Monsanto Moving Die Rheometer MDR 2000E. Rubber compounds were then vulcanized at $160^{\circ} \mathrm{C}$ and 200 bar of pressure in a thermofluid heated press (Gumix TP300/450/1).

\subsection{Characterization of Graphene Materials and Their Silicone Composites}

The chemical composition of graphene materials (GMs) was evaluated by elemental analysis with a LECO-CHNS-932 microanalyzer and X-ray photoelectron spectroscopy (XPS) on a SPECS system operating under $10^{-7}$ Pa connected to a $\mathrm{MgK}_{\alpha}$ X-ray source $(100 \mathrm{~W})$. The $\mathrm{C} 1$ s peak was fitted using a pseudo-Voigt function.

X-ray diffractograms were recorded in a Bruker D8 Advance diffractometer with a radiation frequency of $\mathrm{CuK}_{\alpha 1}(1.5406 \AA$ ) with a power supply of $40 \mathrm{kV}$ and $40 \mathrm{~mA}$. All the XRD patterns were obtained at steps of 0.01 and intervals of $6 \mathrm{~s}$ per step. The crystallite sizes along the c-axis $\left(L_{c}\right)$, and 
a-axis $\left(L_{a}\right)$ were obtained by fitting, respectively, the (002) and (100) reflections using the Scherrer equation [24]. A pseudo-Voigt function was used in order to obtain the best fit of the XRD pattern. The interlaminar distance $\left(d_{002}\right)$ and the estimation of the number of layers $(n)$ were obtained from the (002) reflection. s. The number of stacked graphene layers was estimated from $\left(L_{c} / d_{002}\right)+1$.

Raman spectra were recorded on a Renishaw 2000 Confocal Raman Microprobe, (Gloucestershire, UK) from 750 to $3500 \mathrm{~cm}^{-1}$ using a $514.5 \mathrm{~nm}$ argon ion laser. Five measurements were carried out for each sample. The Raman spectra were normalized and, then, the baseline of the spectrum was extracted using Shirley correction before fitting. The resulting first-order Raman spectra were fitted using two Gaussian functions and three pseudo-Voigt profiles from 800 to $2000 \mathrm{~cm}^{-1}$ in five peaks (I, D, D*, G, D') [20].

The specific surface area was calculated from the $\mathrm{N}_{2}$ adsorption isotherms at $77 \mathrm{~K}$ using the BET equation. The isotherms were obtained using an ASAP 2020 Micromeritics equipment. The samples were outgassed at $300{ }^{\circ} \mathrm{C}$ for $3 \mathrm{~h}$ under vacuum prior to the test.

The dispersion degree of TRGO in the rubber compound was analyzed using a TEM JEOL 2000 EX-II instrument operating at $160 \mathrm{keV}$.

The thermal conductivity of the composites was studied in a stationary flow equipment (LaserComp FOX50) at $25^{\circ} \mathrm{C}$, ASTM C518. The geometry of the samples was square-shaped with dimensions of $25 \times 25 \times 6 \mathrm{~mm}^{3}$.

The impedance measurements of the composites were determined on an ALPHA high-resolution dielectric analyzer (Novocontrol Technologies $\mathrm{GmbH}$ ) in a frequency range of $10^{-1}-10^{7} \mathrm{~Hz}$ at room temperature. The geometry of samples was circular with a diameter of $20 \mathrm{~mm}$ and a thickness of $\approx 200 \mu \mathrm{m}$. The films were held in the dielectric cell between two parallel gold-plated electrodes. The amplitude of the alternating electric current signal applied to the samples was $1 \mathrm{~V}$. The dielectric response was evaluated by measuring the complex permittivity, $\varepsilon^{*}=\varepsilon^{\prime}(\omega)+j \varepsilon^{\prime \prime}(\omega)$ as a function of the frequency $(\omega)$. The AC conductivity was measured in the same condition. The DC conductivity $\left(\sigma_{\mathrm{DC}}\right)$ was calculated using the well-known relation between AC conductivity $\left(\sigma_{\mathrm{AC}}\right)$ and the frequency $(\omega)$ for composite materials [25].

The tensile tests were performed on an Instron uniaxial machine at room temperature, with a cross-head speed of $500 \mathrm{~mm} / \mathrm{min}$, following the ASTM D412 specifications. At least six specimens of each sample were tested to obtain a representative mean value of the results.

The rheological study was performed on an RPA 2000 (Rubber Process Analyzer, Ohio, USA) from Alpha Technologies with a deformation of $6.98 \%$ and a frequency of $1.667 \mathrm{~Hz}$ at $160{ }^{\circ} \mathrm{C}$ for $45 \mathrm{~min}$.

The number of active network chain segments per unit of volume (crosslinking density) was determined using solvent-swelling measurements (toluene and n-heptane for $72 \mathrm{~h}$ at $30{ }^{\circ} \mathrm{C}$ ) by application of the Flory-Rhener equation [26].

\section{Results and Discussion}

\subsection{Characterization of Graphene Materials}

Table 1 summarizes the most relevant features of graphene materials used in this study. The morphological and structural changes coming from the thermal reduction have been discussed in detail in previous studies [21,23]. The most significant characteristics arising from the reduction temperature that can influence the properties of the silicone rubber composites are: (i) a gradual increase of the $\mathrm{C} / \mathrm{O}$ ratio, (ii) a higher restoration of the pristine graphitic 2D-structure, (iii) an increase of the structural order, and (iv) a higher number of layers. On the other hand, the specific surface BET gradually increases with the temperature up to $700{ }^{\circ} \mathrm{C}$, reaching a maximum value of $487 \mathrm{~m}^{2} / \mathrm{g}$, decreasing drastically at higher temperatures to $161 \mathrm{~m}^{2} / \mathrm{g}$ for TRGO- $2000{ }^{\circ} \mathrm{C}$. 


\subsection{Morphology of TRGO Filled Silicone Rubber Composites}

Figure 1 shows TEM images of different TRGO filled silicone composites at 5 phr. TRGO reduced to temperatures up to $1000{ }^{\circ} \mathrm{C}$, are homogeneously dispersed in the silicone matrix forming an interconnected network with a small distance between fillers. However, TRGO reduced at $2000{ }^{\circ} \mathrm{C}$ shows a worse dispersion with the presence of large aggregates. These aggregates are the result of the reduction temperature, $2000{ }^{\circ} \mathrm{C}$, which almost completely removes the oxygen groups and increases the aromaticity of the graphitic structure and the number of layers (Table 1). This morphology prevents the formation of an interconnected filler structure.
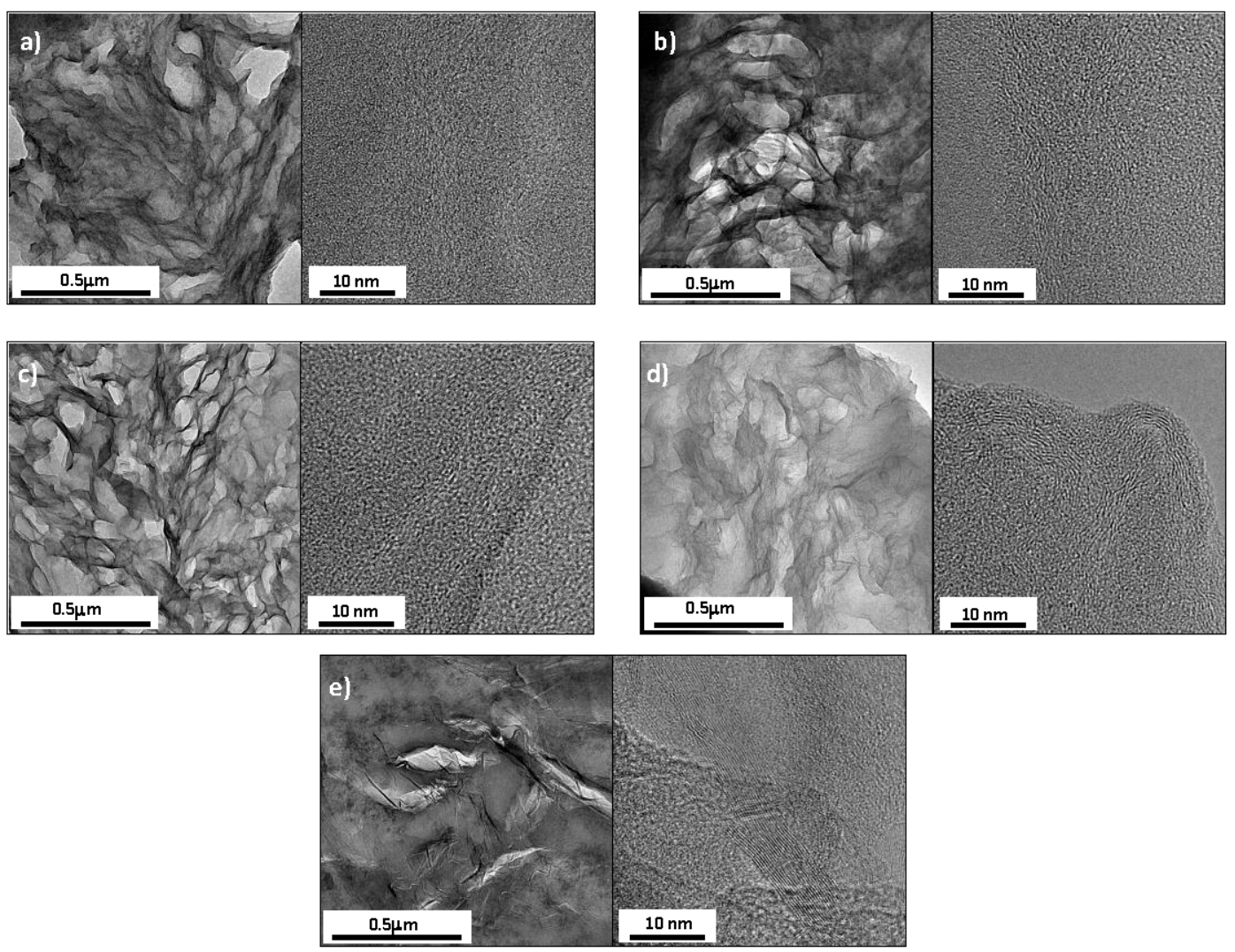

Figure 1. TEM images of thermally reduced graphene oxide (TRGO) filled silicone rubber composites at 5 phr: (a) SR/TRGO-400, (b) SR/TRGO-500, (c) SR/TRGO-700, (d) SR/TRGO-1000 and (e) SR/TRGO-2000. 
Table 1. Composition, and morphological and structural parameters of graphene materials.

\begin{tabular}{|c|c|c|c|c|c|c|c|c|c|c|c|c|c|c|c|c|c|c|c|}
\hline \multirow[b]{2}{*}{ Sample } & \multicolumn{6}{|c|}{ Elemental Analysis (wt.\%) } & \multicolumn{7}{|c|}{ XPS (\%) } & \multirow{2}{*}{$\frac{\mathrm{S}_{\mathrm{BET}}}{\left(\mathrm{m}^{2} / \mathrm{g}\right)}$} & \multicolumn{4}{|c|}{ XRD } & \multirow{2}{*}{$\begin{array}{c}\begin{array}{c}\text { Raman } \\
\text { Spectroscopy }\end{array} \\
I_{\mathrm{D}} / I_{\mathrm{G}}\end{array}$} \\
\hline & C & $\mathrm{O}$ & $\mathbf{N}$ & $\mathrm{s}$ & H & $\mathrm{C} / \mathrm{O}$ & $\mathrm{Csp}^{2}$ & $\mathrm{Csp}^{3}$ & $\mathrm{C}-\mathrm{OH}$ & C-O-C & $>\mathrm{C}=\mathrm{O}$ & $\mathrm{COOH}$ & $\pi-\pi^{*}$ & & $\begin{array}{c}d_{002} \\
(\mathrm{~nm})\end{array}$ & $\begin{array}{c}L_{c} \\
(\mathrm{~nm})\end{array}$ & $\begin{array}{c}L_{a} \\
(\mathrm{~nm})\end{array}$ & $n$ & \\
\hline Graphite oxide & 48.2 & 49.3 & 0.1 & 0.3 & 2.1 & 0.98 & $6.0 \pm 1.3$ & $35.8 \pm 5.0$ & $6.1 \pm 1.2$ & $27.7 \pm 2.3$ & $11.5 \pm 5.9$ & $13.0 \pm 3.6$ & 0.0 & 45 & 0.852 & 9.60 & 26.20 & 12 & $1.12 \pm 0.03$ \\
\hline TRGO-400 & 79.1 & 18.8 & 0.2 & 0.4 & 1.5 & 4.21 & $44.9 \pm 1.5$ & $25.9 \pm 0.6$ & $10.1 \pm 0.1$ & $10.5 \pm 0.1$ & $3.0 \pm 0.1$ & $5.5 \pm 0.9$ & 0.0 & 342 & 0.357 & 1.50 & 7.31 & 4 & $1.29 \pm 0.08$ \\
\hline TRGO-500 & 81.0 & 17.4 & 0.2 & 0.3 & 1.1 & 4.66 & $46.9 \pm 0.4$ & $24.1 \pm 0.1$ & $11.1 \pm 0.1$ & $9.7 \pm 0.4$ & $2.5 \pm 0.1$ & $5.7 \pm 0.1$ & 0.0 & 400 & 0.357 & 1.75 & 7.31 & 4 & $1.19 \pm 0.02$ \\
\hline TRGO-700 & 91.0 & 8.0 & 0.3 & 0.0 & 0.7 & 11.38 & $53.9 \pm 0.1$ & $18.5 \pm 6.4$ & $10.8 \pm 3.0$ & $8.8 \pm 1.1$ & $4.8 \pm 1.6$ & $3.2 \pm 0.9$ & 0.0 & 487 & 0.347 & 1.57 & 7.83 & 4 & $1.20 \pm 0.02$ \\
\hline TRGO-1000 & 98.6 & 1.0 & 0.0 & 0.0 & 0.4 & 98.6 & $67.8 \pm 0.3$ & $15.1 \pm 0.3$ & $11.7 \pm 1.2$ & 0.0 & $4.2 \pm 0.2$ & 0.0 & $1.2 \pm 0.1$ & 467 & 0.360 & 1.39 & 8.43 & 5 & $1.48 \pm 0.05$ \\
\hline TRGO-2000 & 99.7 & 0.2 & 0.0 & 0.0 & 0.1 & 498.5 & $82.7 \pm 1.3$ & $10.1 \pm 0.3$ & $5.9 \pm 1.3$ & 0.0 & 0.0 & 0.0 & $1.3 \pm 0.2$ & 161 & 0.341 & 6.10 & 11.56 & 19 & $0.18 \pm 0.08$ \\
\hline
\end{tabular}




\subsection{Mechanical Properties of TRGO Filled Silicone Rubber Composites}

The mechanical behavior of silicone/TRGO composite materials is shown in Table 2. All TRGOs act as effective reinforcing agents, increasing the value of tensile strength at several deformations, $50 \%$, $100 \%, 300 \%$ and $500 \%$. In general, this reinforcing effect gradually increases with the filler concentration in the composite. However, there are clear differences as a function of the temperature used for reducing the TRGO. It is evident that the structural characteristics and the chemical composition of TRGO have a strong influence on the final mechanical properties of the material. This different behavior of TRGOs is mainly due to the combination of two critical parameters, the specific surface area BET and the oxygen content [27]. Thus, TRGOs-700 and 1000 with larger surface areas, 487 and $467 \mathrm{~m}^{2} / \mathrm{g}$, respectively, are the most reinforcing fillers since they have a better dispersion in the silicone matrix (Figure 1). Larger surface areas should lead to a greater number of contacts between the filler and the matrix, resulting in stronger interfacial interactions.

Tensile strength at low deformations increases by over $170 \%$ and $360 \%$ for TRGO-700 and TRGO-1000, respectively, with $5 \mathrm{phr}$ of filler. The greater reinforcing effect of TRGO-1000 can be due to its lower functional group content. During the vulcanization process, the peroxide undergoes a homolytic breakage producing highly reactive alkoxy radicals, which abstract an $\mathrm{H}$-atom from the silicone, and form polymeric-macroradicals. Two macroradicals then combine to form a covalent crosslink. However, there are many secondary reactions that would lead to a decrease in the efficiency of peroxide as a crosslinking agent. Some of these reactions involve the own reorganization of the radical peroxide, abstraction of hydrogen from another donor different from the backbone of the polymer and the presence of oxygen [28]. Therefore, it is necessary to take into account these possible secondary reactions to be able to interpret the mechanical properties of SR/TRGO composites. TRGO-700 with a higher oxygen content, around $8 \mathrm{wt} \%$ compared to $1 \mathrm{wt} \%$ of TRGO-1000, is susceptible to form secondary reactions parallel to the crosslinking process, such as abstraction of protons from the alcohol of the carboxylic groups [29], or recombination with the epoxy groups [30] present in the basal plane. In fact, the TRGO filled silicone composites with a smaller surface area and higher oxygen content, TRGO-400 and TRGO-500, show the worst mechanical properties, because they partly inhibit the peroxide vulcanization reaction. Hence, the reinforcing effect of TRGO is ascribed to the combination of two factors: the surface area and the number of oxygen groups. TRGO is more effective the larger its surface and the lower the content of oxygen groups on its surface.

Table 2. Tensile properties of TRGO filled silicone rubber composites.

\begin{tabular}{|c|c|c|c|c|c|c|c|}
\hline \multicolumn{2}{|c|}{ Sample } & $\begin{array}{c}\text { Stress at } \\
50 \%(\mathrm{MPa})\end{array}$ & $\begin{array}{c}\text { Stress at } \\
100 \%(\mathrm{MPa})\end{array}$ & $\begin{array}{c}\text { Stress at } \\
300 \%(\mathrm{MPa})\end{array}$ & $\begin{array}{c}\text { Stress at } \\
500 \%(\mathrm{MPa})\end{array}$ & $\begin{array}{c}\text { Maximum } \\
\text { Stress (MPa) }\end{array}$ & $\begin{array}{l}\text { Deformation } \\
\text { at Break }(\%)\end{array}$ \\
\hline \multicolumn{2}{|l|}{ SR } & $0.46 \pm 0.01$ & $0.66 \pm 0.02$ & $1.84 \pm 0.04$ & $3.74 \pm 0.10$ & $7.28 \pm 0.77$ & $742 \pm 40$ \\
\hline \multirow{3}{*}{$\begin{array}{l}\text { TRGO-400 } \\
\text { (phr) }\end{array}$} & 1 & $0.50 \pm 0.02$ & $0.76 \pm 0.02$ & $2.13 \pm 0.03$ & $4.09 \pm 0.04$ & $6.60 \pm 0.75$ & $682 \pm 46$ \\
\hline & 3 & $0.48 \pm 0.02$ & $0.73 \pm 0.02$ & $1.68 \pm 0.05$ & $2.96 \pm 0.08$ & $5.43 \pm 0.38$ & $772 \pm 26$ \\
\hline & 5 & $0.56 \pm 0.01$ & $0.85 \pm 0.01$ & $1.72 \pm 0.01$ & $2.82 \pm 0.03$ & $4.19 \pm 0.17$ & $701 \pm 27$ \\
\hline \multirow{3}{*}{$\begin{array}{c}\text { TRGO-500 } \\
\text { (phr) }\end{array}$} & 1 & $0.53 \pm 0.01$ & $0.81 \pm 0.01$ & $2.27 \pm 0.02$ & $4.33 \pm 0.06$ & $7.18 \pm 0.67$ & $697 \pm 39$ \\
\hline & 3 & $0.83 \pm 0.02$ & $1.32 \pm 0.02$ & $3.26 \pm 0.05$ & $5.47 \pm 0.10$ & $6.49 \pm 0.40$ & $579 \pm 22$ \\
\hline & 5 & $0.77 \pm 0.02$ & $1.19 \pm 0.02$ & $2.35 \pm 0.02$ & $3.69 \pm 0.02$ & $4.12 \pm 0.13$ & $559 \pm 15$ \\
\hline \multirow{3}{*}{$\begin{array}{c}\text { TRGO-700 } \\
\text { (phr) }\end{array}$} & 1 & $0.52 \pm 0.02$ & $0.79 \pm 0.03$ & $2.29 \pm 0.06$ & $4.46 \pm 0.10$ & $7.25 \pm 0.32$ & $689 \pm 19$ \\
\hline & 3 & $1.01 \pm 0.03$ & $1.61 \pm 0.04$ & $3.85 \pm 0.06$ & $6.32 \pm 0.03$ & $6.17 \pm 0.54$ & $493 \pm 36$ \\
\hline & 5 & $1.16 \pm 0.02$ & $1.80 \pm 0.01$ & $3.40 \pm 0.03$ & -- & $3.73 \pm 0.14$ & $342 \pm 19$ \\
\hline \multirow{3}{*}{$\begin{array}{l}\text { TRGO-1000 } \\
\text { (phr) }\end{array}$} & 1 & $0.61 \pm 0.02$ & $0.94 \pm 0.02$ & $2.70 \pm 0.03$ & $5.18 \pm 0.08$ & $7.28 \pm 0.49$ & $633 \pm 28$ \\
\hline & 3 & $0.88 \pm 0.04$ & $1.42 \pm 0.06$ & $3.77 \pm 0.09$ & $6.49 \pm 0.09$ & $6.97 \pm 0.35$ & $532 \pm 23$ \\
\hline & 5 & $1.80 \pm 0.04$ & $3.06 \pm 0.06$ & -- & -- & $6.00 \pm 0.21$ & $247 \pm 10$ \\
\hline \multirow{3}{*}{$\begin{array}{l}\text { TRGO-2000 } \\
\text { (phr) }\end{array}$} & 1 & $0.50 \pm 0.01$ & $0.72 \pm 0.01$ & $1.96 \pm 0.04$ & $3.86 \pm 0.09$ & $7.01 \pm 0.05$ & $710 \pm 29$ \\
\hline & 3 & $0.66 \pm 0.02$ & $1.07 \pm 0.02$ & $2.95 \pm 0.03$ & $5.33 \pm 0.03$ & $7.48 \pm 0.48$ & $642 \pm 29$ \\
\hline & 5 & $0.74 \pm 0.02$ & $1.25 \pm 0.02$ & $3.04 \pm 0.03$ & $4.98 \pm 0.03$ & $5.99 \pm 0.21$ & $584 \pm 17$ \\
\hline
\end{tabular}


This behavior was corroborated by the rheological analysis carried out to determine the vulcanization curves of the composites (Figure 2). The parameters of the vulcanization reaction are reported in Table 3. The addition of TRGO increases the torque value, this effect being more marked for TRGO-1000. An increase in the torque value is related to a higher cross-linking density, as deduced by swelling measurements (Table 3). Hence, TRGOs with higher surface area and lower oxygen content disperse better in the silicone, forming strong interactions with the rubber matrix.

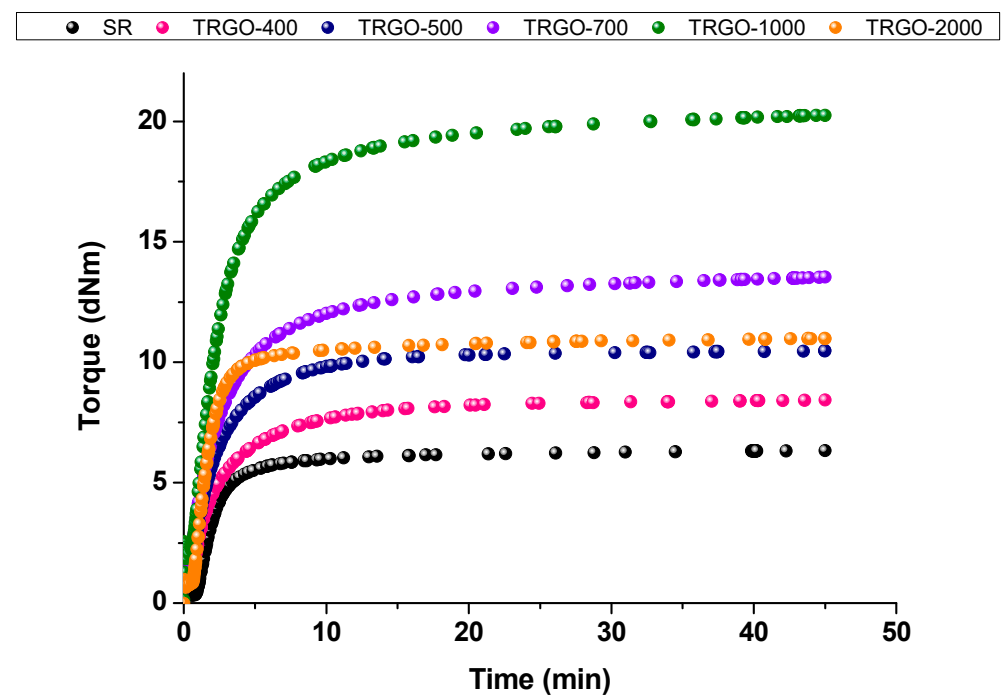

Figure 2. Rheometric curves of TRGO filled silicone composites at $5 \mathrm{phr}$ of filler obtained at $160^{\circ} \mathrm{C}$.

Table 3. Curing characteristics of TRGO filled silicone rubber composites.

\begin{tabular}{|c|c|c|c|c|c|c|c|c|}
\hline \multicolumn{2}{|c|}{ Sample } & $\underset{(\mathrm{dNm})}{S_{\min }}$ & $\begin{array}{c}S_{\max } \\
(\mathrm{dNm})\end{array}$ & $\begin{array}{c}\Delta S \\
(\mathrm{dNm})\end{array}$ & $\begin{array}{c}t_{\mathrm{s} 2} \\
(\mathrm{~min})\end{array}$ & $\begin{array}{c}t_{90} \\
(\mathrm{~min})\end{array}$ & $\begin{array}{c}M c \\
(\mathrm{~g} / \mathrm{mol})\end{array}$ & $\begin{array}{c}v \\
\left(10^{-4} \mathrm{~mol} / \mathrm{cm}^{-3}\right)\end{array}$ \\
\hline \multicolumn{2}{|l|}{ SR } & 0.43 & 8.03 & 7.61 & 1.15 & 6.65 & $7305.6 \pm 190.5$ & $0.68 \pm 0.02$ \\
\hline \multirow{3}{*}{$\begin{array}{c}\text { TRGO-400 } \\
\text { (phr) }\end{array}$} & 1 & 0.39 & 7.63 & 7.24 & 1.23 & 7.06 & $6735.2 \pm 284.4$ & $0.74 \pm 0.03$ \\
\hline & 3 & 0.63 & 7.95 & 7.32 & 1.43 & 13.76 & $6399.0 \pm 744.2$ & $0.79 \pm 0.09$ \\
\hline & 5 & 1.38 & 8.43 & 7.05 & 1.35 & 10.63 & $8374.5 \pm 55.4$ & $0.60 \pm 0.01$ \\
\hline \multirow{3}{*}{$\begin{array}{c}\text { TRGO-500 } \\
\text { (phr) }\end{array}$} & 1 & 0.37 & 7.85 & 7.48 & 1.29 & 7.02 & $6335.0 \pm 86.1$ & $0.79 \pm 0.01$ \\
\hline & 3 & 0.63 & 10.56 & 9.93 & 1.03 & 8.77 & $4733.7 \pm 273.4$ & $1.06 \pm 0.06$ \\
\hline & 5 & 1.58 & 10.48 & 8.90 & 1.14 & 8.49 & $5997.2 \pm 772.2$ & $0.84 \pm 0.11$ \\
\hline \multirow{3}{*}{$\begin{array}{c}\text { TRGO-700 } \\
\text { (phr) }\end{array}$} & 1 & 0.39 & 8.31 & 7.92 & 1.05 & 6.87 & $6508.7 \pm 31.6$ & $0.77 \pm 0.01$ \\
\hline & 3 & 0.80 & 12.44 & 11.64 & 0.94 & 10.00 & $4048.9 \pm 113.5$ & $1.24 \pm 0.03$ \\
\hline & 5 & 1.75 & 13.53 & 11.78 & 0.93 & 12.31 & $3981.4 \pm 113.5$ & $1.26 \pm 0.04$ \\
\hline \multirow{3}{*}{$\begin{array}{l}\text { TRGO-1000 } \\
\text { (phr) }\end{array}$} & 1 & 0.53 & 9.67 & 9.14 & 1.09 & 7.83 & $5949.8 \pm 237.5$ & $0.84 \pm 0.03$ \\
\hline & 3 & 0.78 & 12.54 & 11.76 & 0.85 & 5.95 & $4701.6 \pm 111.5$ & $1.06 \pm 0.03$ \\
\hline & 5 & 1.86 & 20.25 & 18.39 & 0.90 & 10.40 & $2342.6 \pm 140.1$ & $2.07 \pm 0.04$ \\
\hline \multirow{3}{*}{$\begin{array}{l}\text { TRGO-2000 } \\
\text { (phr) }\end{array}$} & 1 & 0.48 & 8.55 & 8.07 & 1.15 & 6.34 & $6097.9 \pm 660.5$ & $0.77 \pm 0.01$ \\
\hline & 3 & 0.56 & 9.83 & 9.27 & 0.95 & 5.75 & $5290.6 \pm 227.1$ & $0.95 \pm 0.04$ \\
\hline & 5 & 0.67 & 10.99 & 10.32 & 1.00 & 4.51 & $4701.6 \pm 111.5$ & $1.06 \pm 0.03$ \\
\hline
\end{tabular}

\subsection{Electrical Properties of TRGO Filled Silicone Rubber Composites}

The electrical conductivity and permittivity in the frequency domain for TRGO filled silicone rubber composites at different loading fractions measured at room temperature are shown in Figure 3. At low TRGO contents, up to $3 \mathrm{phr}$, the AC electrical conductivity of the material is frequency independent with slight variations from pristine silicone. However, by increasing the TRGO content in the composite, $5 \mathrm{phr}$, the electrical conductivity of the material is frequency-dependent, with an increase in the value of the conductivity between four and eight orders of magnitude with respect to pristine silicone. This behavior is typical of a two-phase system commonly described by the percolation 
theory [31], which indicates that at a certain concentration, fillers form interconnected conductive pathways, reaching the electrical percolation threshold.

a

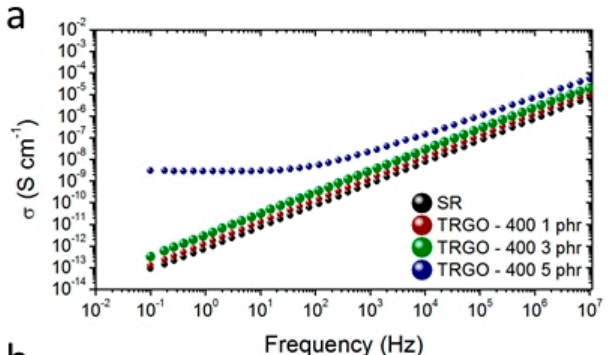

b

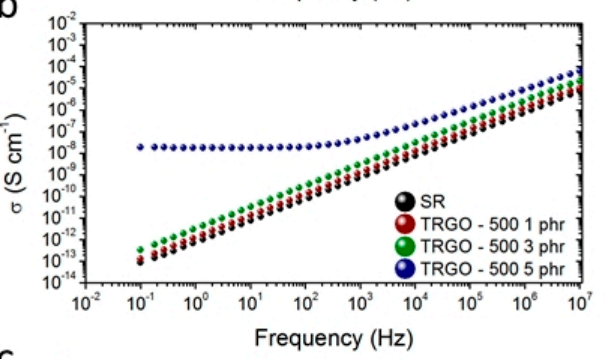

C
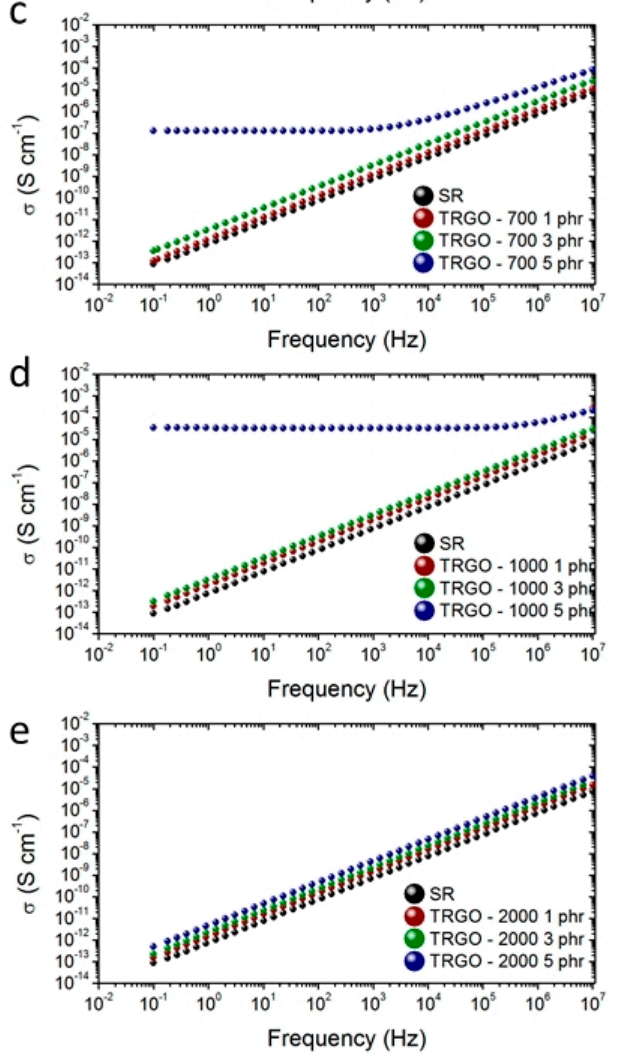

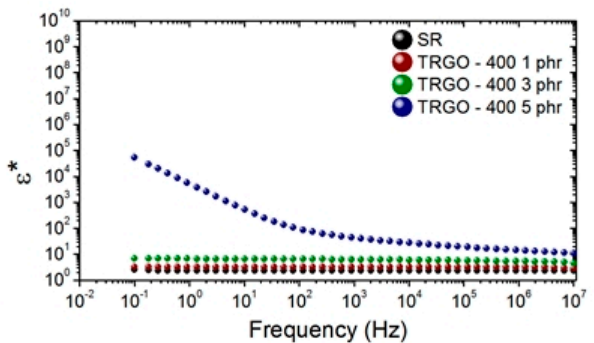

Frequency $(\mathrm{Hz})$
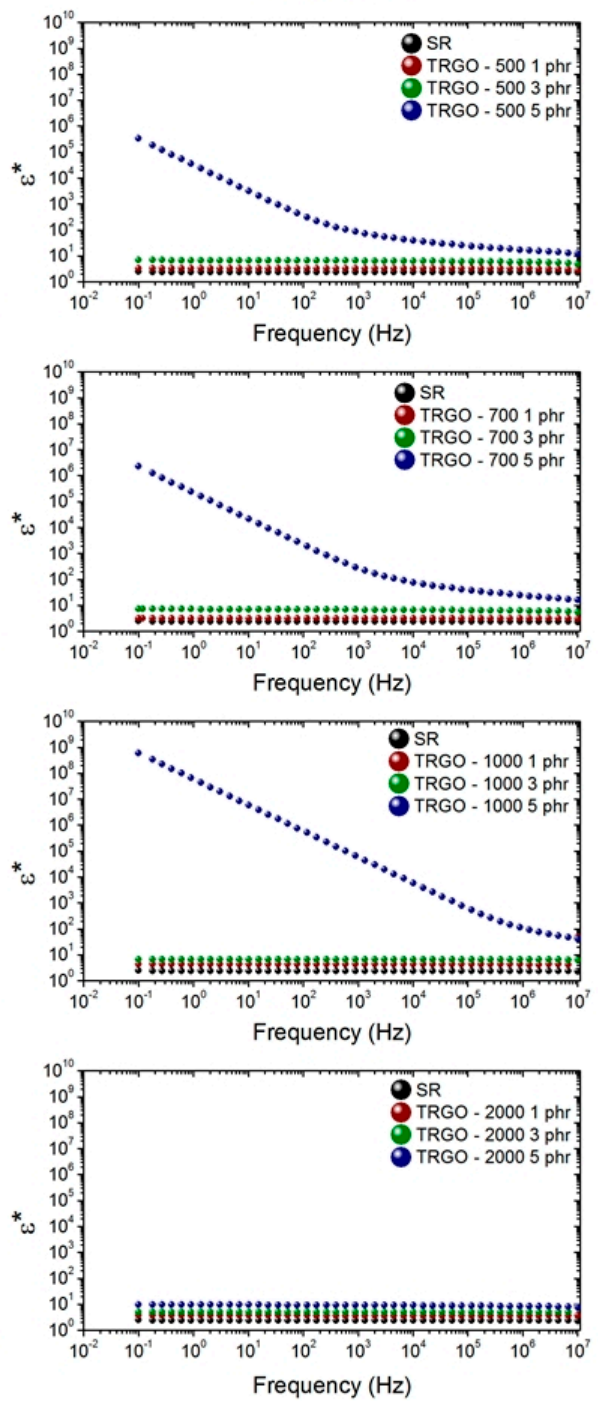

Figure 3. AC electrical conductivity and permittivity for TRGO filled silicone rubber composites at several filler loadings.

In a composite material, the AC conductivity is composed of two terms:

$$
\sigma_{D C}^{*}=\sigma_{D C}+A \omega^{s},
$$

where $\sigma_{D C}$ is the direct current conductivity, $A$ is a pre-exponential factor and $s$ is an experimental parameter with values between 0 and 1 [32]. For insulating materials $s=1$. Hence, from Equation (1), 
the DC conductivity values can be obtained by extrapolating the broadband AC conductivity to $10^{-1} \mathrm{~Hz}$.

Figure 4 shows DC electrical conductivity for the studied silicone/TRGO composites. The dotted lines indicate the electrical percolation threshold for each TRGO. Except TRGO-2000, all TRGOs attain the electrical percolation at loading contents between 3 and $5 \mathrm{phr}$ of filler, and TRGO-1000 at $5 \mathrm{phr}$ exhibits the highest electrical conductivity, with a value of $3.4 \times 10^{-5} \mathrm{~S} / \mathrm{cm}$, higher than those reported in the literature, even at a lower concentration $[10,13]$. This behavior can be attributed to the intrinsic structure of TRGO, with a partial aromatic restoration of the basal plane and to its high specific surface area (Table 1). These parameters favor a good dispersion in the silicone matrix, and enable the electrical conduction via the tunneling effect between adjacent graphene layers [33]. Composites filled with TRGOs-400, 500 and 700 show electrical percolation but with lower electrical conductivity values due to their weak aromatic restoration and the presence of numerous defects (oxygenated groups and atomic vacancies) in the basal plane [21].

The composite filled with TRGO-2000, although having the most aromatic restored lattice in the basal plane, does not reach the percolation threshold even at $5 \mathrm{phr}$ nanofiller content. This may be due to its poor dispersion in the silicone matrix (Figure 1), as the result of its low surface area and absence of oxygen functional groups. This absence causes the stacking of the sheets by $\pi-\pi$ interactions and a poor interaction with the rubber matrix. A similar behavior was observed in a previous work of the authors, based on TRGO filled epoxy resin composites [23].

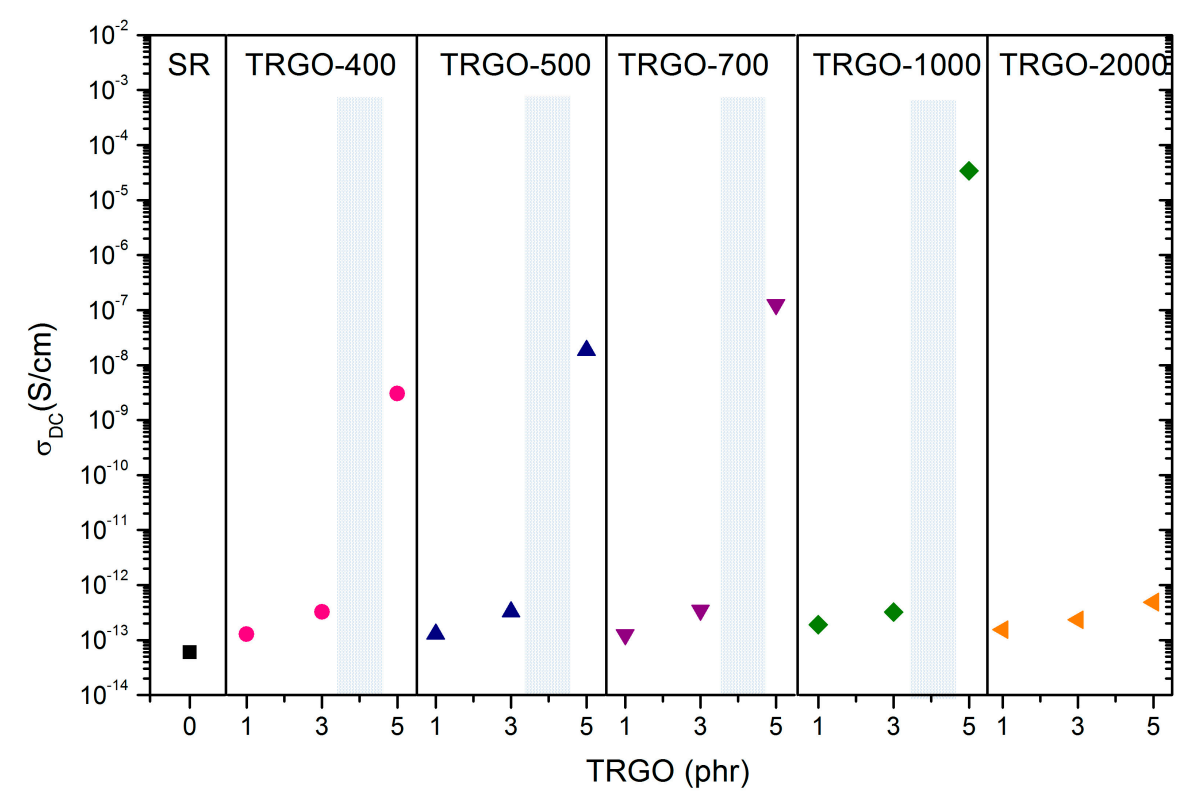

Figure 4. DC electrical conductivity for TRGO filled silicone rubber composites.

On the other hand, the dielectric permittivity hardly varies until the composite material reaches the electrical percolation, where a drastic increase occurs with the frequency. This behavior is associated to the Maxwell-Wagner-Sillars (MWS) effect, typical of composite materials with different dielectric constants [34-36]. This effect is associated to the interfacial polarization due to the migration of charge carriers through the phases of the material.

\subsection{Thermal Conductive of TRGO Filled Silicone Rubber Composites}

The fabrication of thermally conductive elastomers is of great interest to be used as thermal interface materials (TIM) to prevent overheating of electronic devices. The incorporation of conductive fillers with a high aspect ratio, such as graphene, is a feasible strategy to prepare thermally conductive rubber nanocomposites. It has been demonstrated that the sheet-like geometry of graphene may have lower interfacial thermal resistance and, thus, produce larger improvements in the thermal 
conductivity of the polymer composites [37]. Experimental and theoretical studies indicate that any or all factors, including filler type, interfacial bonding, aspect ratio of the fillers, dispersion, and orientation, can affect the thermal conductivity of nanocomposites [38,39]. However, to the best of our knowledge, the effect of structure, chemical composition and morphology of graphene on the thermal conductivity of rubber composite has not been analyzed.

The improvement in thermal conductivity of TRGO filled silicone rubber composites at several concentrations is shown in Figure 5 left. The thermal conductivity of the material gradually increases with the TRGO concentration and with the reduction temperature used. TRGO-2000 is the most effective filler, reaching a thermal conductivity value of $0.349 \mathrm{~W} / \mathrm{mK}$, which is a $78 \%$ increase over pristine silicone. In contrast to the orders of magnitude enhancement in electrical conductivity previously observed, the thermal conductivity of the nanocomposite only exhibits modest improvements, and no percolation transition is observed. This behavior is due to the interfacial thermal resistance, which acts as barrier to heat flow and originates from the mismatch in the phonon spectra of the two phases and possible weak contact at the interface [40].

Unlike other studies, where the functionalization of carbon nanoparticles improved the thermal conductivity of the composite material [14], in our case, the best results were obtained with TRGO-2000, without functional groups in its structure. This increase is associated with the large aromatic restoration and a more compact structure achieved with the heat treatment at $2000{ }^{\circ} \mathrm{C}$. This TRGO exhibits a higher particle size and a greater number of stacked layers, around 19 (Table 1). These characteristics result in the formation of large aggregates that minimizes the coupling losses due to effective diffusion of phonons across the aggregates [41]. Similar results were observed by other authors, who demonstrated that the composites containing large particles have superior thermal conductivity compared to those filled with small particles [42-44]. It is evident that there is a close relationship between the percentage of restoration of the pristine graphitic 2D-structure, and the ability of the material to dissipate heat (Figure 5 right).

Although TRGO-1000 showed a better dispersion, as corroborated by TEM (Figure 1), the thermal conductivity of the composite is lower than TRGO-2000 due to the presence of large defects in the basal plane and a higher number of interfaces, which would hinder the correct transition of phonons.
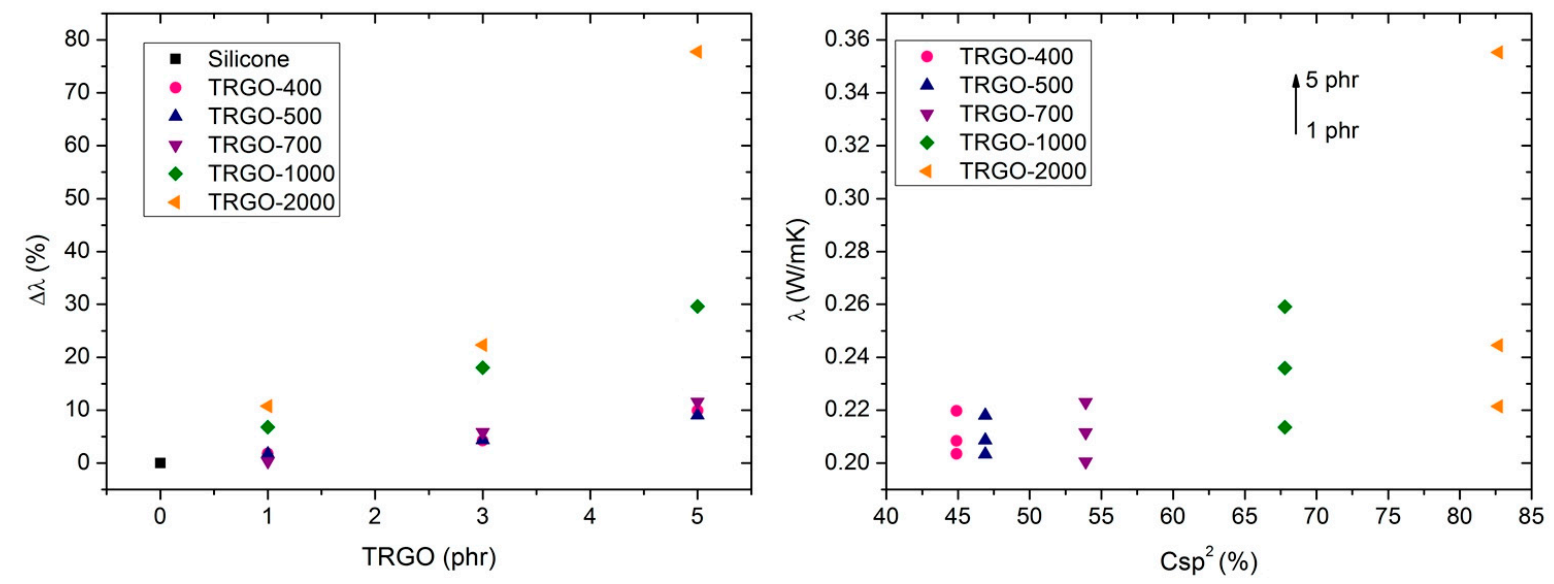

Figure 5. (left) Thermal conductivity enhancement of TRGO filled silicone rubber composites at $25^{\circ} \mathrm{C}$ and (right) variation of the thermal conductivity as a function of $\mathrm{Csp}^{2}$ percentage.

\section{Conclusions}

Multifunctional rubber nanocomposites with performance enhancement were designed using an industrial manufacturing methodology. We have demonstrated that it is possible to modulate the mechanical properties and transport phenomena of TRGO filled silicone rubber composites, controlling the morphological and structural characteristics of TRGO, as well as its concentration in the composite material. Thus, TRGOs with high specific surface area and a partial aromatic restoration are ideal fillers 
to improve the mechanical properties and provide electrical conductivity to the polymer. Meanwhile, TRGOs with a large particle size and aromatic restoration are the most effective to produce thermally conductive elastomer nanocomposites.

The ability to control thermal conductivity of elastomer nanocomposites is a highly desirable property, which can be exploited in applications that may require a material to be thermally conductive but electrically insulating such as in power electronics, electric motors, etc.

Author Contributions: R.S.-H. and R.V. performed the experiments; R.M., R.V. and M.A.L.-M. conceived and designed the experiments; R.S.-H., R.V. and C.B. analyzed the data and R.M. and M.A.L.-M. wrote the paper.

Funding: This research was funded by MINECO, grant number MAT2016-81138-R. R.S. thanks to MINECO for the Predoctoral grant BES-2014-070802.

Conflicts of Interest: The authors declare no conflict of interest.

\section{References}

1. Shit, S.C.; Shah, P. A Review on Silicone Rubber. Natl. Acad. Sci. Lett. USA 2013, 36, 355-365. [CrossRef]

2. Stieghorst, J.; Majaura, D.; Wevering, H.; Doll, T. Toward 3D Printing of Medical Implants: Reduced Lateral Droplet Spreading of Silicone Rubber under Intense IR Curing. ACS Appl. Mater. Interfaces 2016, 8, 8239-8246. [CrossRef] [PubMed]

3. Zhang, H.; Lin, Y.; Zhang, D.; Wang, W.; Xing, Y.; Lin, J.; Hong, H.; Li, C. Graphene Nanosheet/Silicone Composite with Enhanced Thermal Conductivity and its Application in Heat Dissipation of High-Power Light-emitting Diodes. Curr. Appl. Phys. 2016, 16, 1695-1702. [CrossRef]

4. Chen, C.Y.; Pu, N.W.; Liu, Y.M.; Huang, S.Y.; Wu, C.H.; Ger, M.D.; Gong, Y.J.; Chou, Y.C. Remarkable Microwave Absorption Performance of Graphene at a Very Low Loading Ratio. Compos. Part B 2017, 114, 395-403. [CrossRef]

5. He, Z.; Chen, Y.; Jian Yang, J.; Tang, C.; Lv, J.; Liu, Y.; Mei, J.; Lau, W.M.; Hui, D. Fabrication of Polydimethylsiloxane Films with Special Surface Wettability by 3D Printing. Compos. Part B 2017, 129, 58-65. [CrossRef]

6. Yang, H.; Yao, X.; Zheng, Z.; Gong, L.; Yuan, L.; Yuan, Y.; Liu, Y. Highly Sensitive and Stretchable Graphene-Silicone Rubber Composites for Strain Sensing. Compos. Sci. Technol. 2018, 167, 371-378. [CrossRef]

7. Ferrari, A.C.; Meyer, J.C.; Scardaci, V.; Casiraghi, C.; Lazzeri, M.; Mauri, F.; Piscanec, S.; Jiang, D.; Novoselov, K.S.; Roth, S.; et al. Raman Spectrum of Graphene and Graphene Layers. Phys. Rev. Lett. 2006, 97, 187401-187404. [CrossRef]

8. Gomez-Navarro, C.; Meyer, J.C.; Sundaram, R.S.; Chuvilin, A.; Kurasch, S.; Burghard, M.; Kern, K.; Kaiser, U. Atomic Structure of Reduced Graphene Oxide. Nano Lett. 2010, 10, 1144-1148. [CrossRef]

9. Zhu, Y.; Murali, S.; Cai, W.; Li, X.; Suk, J.W.; Potts, J.R.; Ruoff, R.S. Graphene and Graphene Oxide: Synthesis, Properties, And Applications. Adv. Mater. 2010, 22, 3906-3924. [CrossRef]

10. Song, Y.; Yu, J.; Yu, L.; Alam, F.E.; Dai, W.; Jiang, N. Enhancing the Thermal, Electrical, and Mechanical Properties of Silicone Rubber by Addition of Graphene Nanoplatelets. Mater. Des. 2015, 88, 950-957. [CrossRef]

11. Shi, G.; Zhao, Z.; Pai, J.H.; Lee, I.; Zhang, L.; Stevenson, C.; Ishara, K.; Zhang, R.; Zhu, H.; Ma, J. Highly Sensitive, Wearable, Durable Strain Sensors and Stretchable Conductors Using Graphene/Silicon Rubber Composites. Adv. Funct. Mater. 2016, 26, 7614-7625. [CrossRef]

12. Zhao, X.W.; Zang, C.G.; Wen, Y.G.; Jiao, Q.J. Thermal and Mechanical Properties of Liquid Silicone Rubber Composites Filled with Functionalized Graphene Oxide. J. Appl. Polym. Sci. 2015, 42582. [CrossRef]

13. Zhang, G.; Wang, F.; Dai, J.; Huang, Z. Effect of Functionalization of Graphene Nanoplatelets on the Mechanical and Thermal Properties of Silicone Rubber Composites. Materials 2016, 9, 92. [CrossRef] [PubMed]

14. Chen, T.; Liu, B. Improvement of Thermal Conductivities for Silicone Nanocomposite Via Incorporating Poly $(\gamma$-methacryloxypropyltrimethoxy silane) Grafted Graphene Fillers. Chem. Phys. Lett. 2018, 693, 121-126. [CrossRef]

15. Song, J.; Chen, C.; Zhang, Y. High Thermal Conductivity and Stretchability of Layer-by-Layer Assembled Silicone Rubber/Graphene Nanosheets Multilayered Films. Compos. Part A 2018, 105, 1-8. [CrossRef] 
16. Qiu, X.; Cai, H.; Fang, X.; Zheng, J. The Improved Thermal Oxidative Stability of Silicone Rubber by Incorporating Reduced Graphene Oxide; Impact Factors and Action Mechanism. Polym. Compos. 2018, 39, 1105-1115. [CrossRef]

17. Wang, Y.; Qiu, X.; Zheng, J. Effect of the Sheet Size on the Thermal Stability of Silicone Rubber-Reduced Graphene Oxide Nanocomposites. J. Appl. Polym. Sci. 2019, 136, 47034. [CrossRef]

18. Papageorgiou, D.G.; Kinloch, I.A.; Young, R.J. Graphene/Elastomer Nanocomposites. Carbon 2015, 95, 460-484. [CrossRef]

19. Mensah, B.; Gupta, K.C.; Kim, H.; Wang, W.; Jeong, K.; Nah, C. Graphene-Reinforced Elastomeric Nanocomposites: A review. Polym. Test. 2018, 68, 160-184. [CrossRef]

20. Botas, C.; Álvarez, P.; Blanco, C.; Santamaría, R.; Granda, M.; Ares, P.; Rodríguez-Reinoso, F.; Menéndez, R. The Effect of the Parent Graphite on the Structure of Graphene Oxide. Carbon 2012, 50, 275-282. [CrossRef]

21. Botas, C.; Álvarez, P.; Blanco, P.; Granda, M.; Blanco, C.; Santamaría, R.; Romasanta, L.J.; Verdejo, R.; López-Manchado, M.A.; Menéndez, R. Graphene Materials with Different Structures Prepared from the same Graphite by the Hummers and Brodie Methods. Carbon 2013, 65, 156-164. [CrossRef]

22. Vazquez-Moreno, J.M.; Yuste-Sanchez, V.; Sanchez-Hidalgo, R.; Verdejo, R.; Lopez-Manchado, M.A.; Fernández-García, L.; Blanco, C.; Menéndez, R. Customizing Thermally-Reduced Graphene Oxides for Electrically Conductive or Mechanical Reinforced Epoxy Nanocomposites. Eur. Polym. J. 2017, 93, 1-7. [CrossRef]

23. Sanchez-Hidalgo, R.; Yuste-Sanchez, V.; Verdejo, R.; Blanco, C.; Lopez-Manchado, M.A.; Menéndez, R. Main Structural Features of Graphene Materials Controlling the Transport Properties of Epoxy Resin-based Composites. Eur. Polym. J. 2018, 101, 56-65. [CrossRef]

24. Patterson, A.L. The Scherrer Formula for X-Ray Particle Size Determination. Phys. Rev. 1939, 56, 978-982.

25. Martin-Gallego, M.; Verdejo, R.; Lopez-Manchado, M.A.; Sangermano, M. Epoxy-Graphene UV-Cured Nanocomposites. Polymer 2011, 52, 4664-4669. [CrossRef]

26. Flory, P.J. Principles of Polymer Chemistry; Cornell University: Ithaca, NY, USA, 1953.

27. Aguilar-Bolados, H.; Lopez-Manchado, M.A.; Brasero, J.; Avilés, F.; Yazdani-Pedram, M. Effect of the Morphology of Thermally Reduced Graphite Oxide on the Mechanical and Electrical Properties of Natural Rubber Nanocomposites. Compos. Part B 2016, 87, 350-356. [CrossRef]

28. Dluzneski, P.R. Peroxide Vulcanization of Elastomers. Rubber Chem. Technol. 2001, 74, 451-492. [CrossRef]

29. Chu, Y.L.; Chen, Y.A.; Li, W.C.; Chu, J.H.; Chen, C.H.; Chiang, C.M. Mechanistic Insights into Light-Driven Graphene-Induced Peroxide Decomposition: Radical Generation and Disproportionation. Chem. Commun. 2016, 52, 9291-9294. [CrossRef]

30. Meleshevich, A.P. Reactions of Epoxy-Compounds by a Radical Mechanism. Russ. Chem. Rev. 1970, $39,213$. [CrossRef]

31. Chatterjee, S.; Nafezarefi, F.; Tai, N.H.; Schlagenhauf, L.; Nüesch, F.A.; Chu, B.T.T. Size and Synergy Effects of Nanofiller Hybrids Including Graphene Nanoplatelets and Carbon Nanotubes in Mechanical Properties of Epoxy Composites. Carbon 2012, 50, 5380-5386. [CrossRef]

32. Martin-Gallego, M.; Hernández, M.; Lorenzo, V.; Verdejo, R.; Lopez-Manchado, M.A.; Sangermano, M. Cationic Photocured Epoxy Nanocomposites Filled with Different Carbon Fillers. Polymer 2012, 53, 1831-1838. [CrossRef]

33. Toker, D.; Azulay, D.; Shimoni, N.; Balberg, I.; Millo, O. Tunneling and Percolation in Metal-Insulator Composite Materials. Phys. Rev. B Condens. Matter Mater. Phys. 2003, 68, 041403. [CrossRef]

34. Hernández, M.; Carretero-González, J.; Verdejo, R.; Ezquerra, T.; López-Manchado, M.A. Molecular Dynamics of Natural Rubber/Layered Silicate Nanocomposites as Studied by Dielectric Relaxation Spectroscopy. Macromolecules 2010, 43, 643-651. [CrossRef]

35. Martin-Gallego, M.; Bernal, M.M.; Hernandez, M.; Verdejo, R.; Lopez-Manchado, M.A. Comparison of Filler Percolation and Mechanical Properties in Graphene and Carbon Nanotubes Filled Epoxy Nanocomposites. Eur. Polym. J. 2013, 49, 1347-1353. [CrossRef]

36. Aguilar-Bolados, H.; Brasero, J.; Lopez-Manchado, M.A.; Yazdani-Pedram, M. High Performance Natural Rubber/Thermally Reduced Graphite Oxide Nanocomposites by Latex Technology. Compos. Part B 2014, 67, 449-454. [CrossRef] 
37. Yu, A.P.; Ramesh, P.; Sun, X.B.; Bekyarova, E.; Itkis, M.E.; Haddon, R.C. Enhanced Thermal Conductivity in a Hybrid Graphite Nanoplatelet-Carbon Nanotube Filler for Epoxy Composites. Adv. Mater. 2008, 20, 4740-4744. [CrossRef]

38. Han, Z.; Fina, A. Thermal Conductivity of Carbon Nanotubes and their Polymer Nanocomposites: A review. Prog. Polym. Sci. 2011, 36, 914-944. [CrossRef]

39. Li, Z.G.; Wu, W.J.; Chen, H.; Zhu, Z.H.; Wang, Y.S.; Zhang, Y. Thermal Conductivity of micro/nano Filler Filled Polymeric Composites. RSC Adv. 2013, 3, 6417-6428. [CrossRef]

40. Shenogin, S.; Xue, L.; Ozisik, R.; Keblinski, P.; Cahill, D.G. Role of Thermal Boundary Resistance on the Heat Flow in Carbon-Nanotube Composites. J. Appl. Phys. 2004, 95, 8136-8144. [CrossRef]

41. Song, Y.S.; Youn, J.R. Influence of Dispersion States of Carbon Nanotubes on Physical Properties of Epoxy Nanocomposites. Carbon 2005, 43, 1378-1385. [CrossRef]

42. Huang, X.; Xie, L.; Jiang, P.; Wang, G.; Liu, F. Electrical, Thermophysical and Micromechanical Properties of

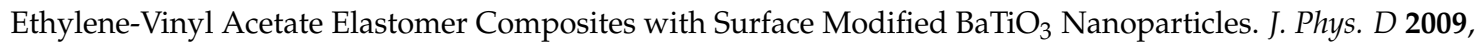
42, 245407. [CrossRef]

43. Zhou, W.Y.; Yu, D.M.; Wang, C.F.; An, Q.L.; Qi, S.H. Effect of Filler Size Distribution on the Mechanical and Physical Properties of Alumina-filled Silicone Rubber. Polym. Eng. Sci. 2008, 48, 1381-1388. [CrossRef]

44. Zhou, W.Y.; Qi, S.H.; Zhao, H.Z.; Liu, N.L. Thermally Conductive Silicone Rubber Reinforced with Boron Nitride Particle. Polym. Compos. 2007, 28, 23-28. [CrossRef]

(C) 2019 by the authors. Licensee MDPI, Basel, Switzerland. This article is an open access article distributed under the terms and conditions of the Creative Commons Attribution (CC BY) license (http://creativecommons.org/licenses/by/4.0/). 